\title{
La canonización de santa Teresa de Jesús
}

The canonization of St. Teresa of Ávila

Julen URKIZA, OCD

Convento del Carmen de Markina

karmelaldiz@telefonica.net

Abstract: This article describes the stages in the canonization process of St. Teresa of Ávila (Teresa de Jesús), starting from her death in 1582 and following the various processes, which are exceptionally well documented with testimonies. These begin with the recognition of her heroic virtues and holy life, leading then to her beatification and culminating in her canonization. The accounts of the processes bear witness to the exceptional figure of Teresa of Ávila, a foundress who was famous during her own lifetime for her holiness, and whose reputation spread to an extraordinary extent reaching all levels of society, so that we can speak of it as a socio-religious «phenomenon» in itself.

Keywords: Teresa de Jesús, canonization, canonization processes, Ana de San Bartolomé.
Resumen: Se presenta el camino recorrido en la consecución de la canonización de Teresa de Jesús: comenzó con su muerte en 1582; los procesos, tan ricos y excepcionalmente abundantes en testimonios, nos muestran el camino: del reconocimiento de sus virtudes heroicas y de su santa vida se llegó a su beatificación para culminar con su canonización. En los procesos se constata la figura excepcional de Teresa de Jesús, fundadora, con fama de santidad ya en vida, y especialmente la expansión extraordinaria de su fama y personalidad, su irradiación en todas las capas sociales, hasta convertirse en un «fenómeno» socio-religioso.

Palabras clave: Teresa de Jesús, Canonización, Procesos (de canonización), Ana de San Bartolomé.

La canonización de cinco beatos (Isidro Labrador, Teresa de Jesús, Ignacio de Loyola, Francisco Javier y Felipe Neri) el 12 de marzo de 1622 fue un acontecimiento excepcional, cuya memoria perduraría durante siglos... La calidad, doctrina y mensaje de los personajes significarían mucho para el futuro de los pueblos y de la Iglesia. Menos Isidro, los demás habían vivido en el siglo XVI, siglo de guerras y descubrimientos, de vida y luchas, de reformas y de nuevos movimientos dentro de la Iglesia y de la sociedad, etc.

Una de esas figuras era Teresa de Jesús; fundadora, con fama de santidad ya en vida y con una irradiación extraordinaria, como se constataría en los muchos procesos de beatificación y canonización que se realizaron en varios países. Teresa se nos presenta como esos santos y esas santas que «han sido siempre 
fuente y origen de renovación en las circunstancias más difíciles de la historia de la Iglesia» ${ }^{1}$.

Los procesos de beatificación y canonización de la madre Teresa de Jesús, actualmente ya publicados ${ }^{2}$, que culminaron con la canonización en 1622 , nos presentan la expansión de su fama y personalidad, su irradiación en todas las capas sociales, hasta convertirse en un «fenómeno» socio-religioso. La irradiación de sus milagros y doctrina mística gozaron una expansión extraordinaria.

Así, haremos un recorrido, desde la muerte de la madre Teresa hasta su canonización con la ayuda de los muchos procesos que se han conservado.

\section{MUERTE DE LA MADRE TERESA, INICIO DEL CAMINO HACIA SU CANONIZACIÓN}

\section{Una experiencia mistica clarificadora que irradia bacia el futuro}

En la última escena de la vida de la madre Teresa de Jesús tuvo lugar algo que vislumbraría su porvenir glorioso, una realidad vivida por la beata Ana de San Bartolomé, su amiga íntima, su secretaria, enfermera, colaboradora y heredera.

La madre Teresa quiso morir y murió en los brazos de Ana de San Bartolomé ${ }^{3}$. Hay muchas narraciones sobre la muerte de la madre Teresa, y en buena

1 Juan Pablo II, Exhortación Apostólica Christifideles Laici, 16 (documento de 30 de diciembre 1988); la cita está tomada del sínodo extraordinario de 1985.

2 Procesos de beatificación y canonización de la madre Teresa de fesús. Edición del quinto centenario preparada por Julen Urkiza, OCD: Tomo I: Procesos informativos de los años 1591-1592 Y 15951597, Burgos, 2015, 1146 pp.; Tomo II: Procesos remisoriales de Ávila y Salamanca in genere (1604) y de Madrid in specie (1609-1610). - Procesos compulsoriales de El Escorial, Toledo, Malagón-Daimiel y Salamanca-Alba de Tormes (1609-1610), Burgos, 2015, 1060 pp.; Tomo III: Proceso remisorial de Salamanca y Alba de Tormes in specie (1609-1610), Burgos, 2015, 1299 pp.; Tomo IV: proceso remisorial de Avila in specie (1610). - Procesos compulsoriales de Zaragoza, Segovia, Ávila y Madrid (1610-1611, Burgos, 2015, 1019 pp.; Tomo V: proceso remisorial de Ávila in specie (1610). - Procesos compulsoriales de Zaragoza, Segovia, Avila y Madrid (1610-1611), Burgos, 2016, 1004 pp.; Tomo VI: Últimos pasos de la Sagrada Congregación de Ritos hacia la beatificación y canonización (1609-1622), Burgos, 2016, 959 pp. (BMC 35-40). Y a lo largo de este artículo citamos estos volúmenes abreviadamente con Procesos...

3 Cfr. Autobiografía A 6, 18; Últimos años 2, 27. Aquí mencionamos algunos escritos de Ana de San Bartolomé citados en este artículo, y lo hacemos de forma abreviada y según la última edición BEATA ANA DE SAN BARTOLOMÉ, Obras completas. Nueva edición revisada y aumentada por Julen URKIZA, OCD (Burgos, Monte Carmelo, 2014), 1712 pp.: Autobiografía A (Autobiografía de Amberes); Autobiografía B (Autobiografía de Bolonia); Meditaciones (Meditaciones sobre el camino de Cristo); Relaciones de gracias (Relaciones de gracias místicas); Últimos años (Últimos 
parte de testigos oculares ${ }^{4}$, pero la de su secretaria es la más excepcional por su vivencia mística en ese momento. Era el 4 de octubre de 1582. La Enfermera no se apartaba de la cabecera de la Fundadora. Esta compañía era para la Santa el elemento tranquilizante en aquella hora difícil.

En la agonía de la Madre parecía que era Ana la que estaba en agonía ${ }^{5}$, y sentía que era la Madre la que le quería consolar: «la santa Madre lo pidió a Dios porque se consolase, como la veía con tanta pena y la quería tanto» ${ }^{6}$.

$\mathrm{Al}$ atardecer el $\mathrm{P}$. Antonio de Jesús fue a visitar a la Fundadora, y al ver que Ana todavía estaba allá y no descansaba, le mandó ir a comer algo; ella describe la escena con gran ternura:

Y, en yéndome, no sosegaba la Santa, sino mirando a un cabo y a otro. Y díjola el Padre si me quería, y por señas dijo que sí, y llamáronme. Y viniendo, que me vio, se rio; y me mostró tanta gracia y amor, que me tomó con sus manos y puso en mis brazos su cabeza; y allí la tuve abrazada hasta que espiró, estando yo más muerta que la misma Santa ${ }^{7}$.

En este instante ocurrió algo trascendente y fascinante. Era algo que se recoge en diversas crónicas conventuales y declaraciones de los procesos de beatificación de la madre Teresa, pero difícilmente creíble si la misma Ana no nos lo hubiera descrito. A la hora misma de la muerte de la Santa, no era ésta la que acaparaba la admiración de los presentes ${ }^{8}$, sino su Enfermera. Tenemos la suerte

años de la madre Teresa de Jesús); Cartas; Añadidos (Añadidos de Teresa de Jesús a la relación de María de San Jerónimo); Relación de María (Relación de María de San Jerónimo sobre Ana de San Bartolomé); Relación de Teresa (relación de Teresa de Jesús sobre Ana de San Bartolomé); Anotaciones (Anotaciones de María de San Jerónimo y Teresa de Jesús sobre la vida interior de Ana de San Bartolomé).

4 Cfr. Declaraciones de las religiosas de Alba de Tormes, respuesta a la pregunta 6, sobre la muerte de Teresa, en Procesos..., t. I, pp. 139-202. Véase: Juan Luis AsTigarRaGA, Eulogio PaCHO y Otilio RODRÍGUEZ, Fuentes históricas sobre la muerte y el cuerpo de santa Teresa de Fesús (1582-1596), Roma, 1982, XV-603 pp. (Monumenta Historica Carmeli Teresiani, 6; en adelante abreviamos en MHCT); Julen URKIZA, 'Con el mal de la muerte' y 'la hora del dichoso tránsito'. Manifestaciones de un testigo de excepción, en Revista de Espiritualidad, 159-160 (1981), pp. 311-330.

5 Cfr. ANA DE SAN BARTOlomé, Añadidos 2, 15: «Estando nuestra santa Madre en agonía de la muerte y teniéndole esta hermana en los brazos casi tan muerta como la misma Santa»; Relaciones de gracias 3, 8: «Y poco antes que la Santa expirase, estando en más agonía que nuestra Santa...».

6 ANa DE SAN Bartolomé, Relación de María 2, 17; Relaciones de gracias 3, 8.

7 ANA DE SAN BARTOLOMÉ, Autobiografía A 6,18.

8 ANA DE SAN BARTOLOMÉ, Anotaciones 2, 20: «Y acaeció que del resplandor reverberaban tanto en el rostro de la hermana que las otras religiosas repararon y se ocupaban más en mirarla que a la santa madre». 
de poseer varias versiones de la misma Ana sobre la visión que tuvo en aquel momento en que Ana era la que se sentía como muerta:

El Señor «se me mostró con toda la majestad y compañía de los bienaventurados sobre los pies de su cama, que venían por su alma. Estuvo un Credo esta vista gloriosísima, de manera que tuvo tiempo de mudar mi pena y sentimiento en una gran resignación y pedir perdón al Señor y decirle: 'Señor, si Vuesa Majestad me la quisiera dejar para mi consuelo, os pidiera, ahora que he visto su gloria, que no la dejéis un momento acá.' Y con esto expiró y se fue esta dichosa alma a gozar de Dios como una paloma»?

Como se ve en esta narración y en otras (que muestran la amistad e intimidad en que vivían ambas santas con Dios), con el «consentimiento» de la Enfermera, y en ese instante, se realizó el «dichoso tránsito» de la Madre. Eran las nueve de la noche del día 4 de octubre, día de San Francisco ${ }^{10}$.

La presencia viva de Cristo que Ana veía en la madre Teresa de Jesús era lo que tanto le atraía y estimaba ${ }^{11}$; y más tarde hablaría de la luz de esta presencia viva que resplandecía en Teresa, como señal de su santidad. Cuando hacia 1621-1622 recordaba a los santos, las «estrellas» de su tiempo, describía, aunque brevísimamente, a cada uno: «fray Pedro de Alcántara», «maestro Ávila» (Juan de Ávila), «fray Luis Beltrán», «el padre Francisco de Borja», «nuestro santo y padre fray Juan de la Cruz», y también «un padre Ignacio, que, siendo mundano, le supo buscar a Dios y levantar en su servicio su Orden en tanta perfección, de donde han salido hasta ahora almas santas. Uno es el padre Francisco Javier, que enviándole la obediencia a las Indias, las convirtió y obró Dios en él las maravillas que se muestran en su vida» ${ }^{12} \ldots$

Estas estrellas y otras que no cuento hemos visto a los ojos, y eran flacos y enfermos como nosotras, mas como se han dispuesto, les ha dado Dios las fuerzas que a los pasados. [...] que, dejando los dichos, [la madre Teresa] ha salido como el lucero

9 Ana de san Bartolomé, Autobiografía A 6,19. Entonces quedó Ana con gran consuelo, de forma «que nunca más sintió pena ni nunca hasta hoy la ha sentido de la muerte de la santa Madre» (Declaración de 1595 6). Por la importancia de esta escena podemos recordar aquí las otras versiones en su orden cronológico de redacción: Relación de María 2,17; Relación de Teresa 2,13; Añadidos 2, 15; Declaración de 1595 6; Autobiografía B 6,3; Relaciones de gracias 3,8.

10 ANA DE SAN BARTOlOmé, Últimos años 2, 28; Teresita, la sobrina de la Santa, dice que murió a la misma hora (cfr. Procesos..., t. I, p. 325); lo mismo que otras cuatro religiosas de Alba, que estuvieron presentes (cfr. Procesos..., t. I, pp. 171, 180, 186, 192), mientras otras cuatro dicen que murió entre las 9 y 10 de la noche; y una dice entre las 8 y 9.

11 Véase, por ejemplo, ANA DE SAN BARTOLOMÉ, Autobiografía A 6,16; Autobiografía B 6,2.

12 ANA DE SAN BARTOLOMÉ, Meditaciones 2, 2-5. 
de la mañana que va siempre mirando el sol que sale en pos de él. Así nuestra Santa, sobre las demás estrellas que quedan dichas, es el lucero que miró siempre al sol desde que se le entendió el uso de [la razón]; y mirándola el sol de justicia, infundió en ella los frutos del Espíritu Santo, para que con ellos produjese en la tierra plantas de vida en sus hijos e hijas. Y no sólo en ellas, mas en todo el mundo, y en particular en España, que, levantando ella su Orden, todas las demás se levantaron a su ejemplo y fervor, que estaban caídas [...]. En fin, es el lucero de la mañana que reverberando en ella el sol, hace que sus rayos parezcan más que en las demás ${ }^{13}$.

Esta gloria de la madre Teresa vista por su compañera inseparable se iría haciendo patente en muchísima gente, de manera que muchos pueblos y naciones verían su luz y gozarían de ella... Y esta realidad la constatamos en los muchos procesos que pronto se llevaron a cabo hasta su beatificación y canonización.

\section{Pleito por la posesión de su cuerpo (entre Alba de Tormes y Ávila)}

Ya con su enterramiento comenzó a crecer la fama de su gran personalidad y de su santidad. A la madre Teresa, muerta en el convento de la Encarnación de Alba, se le enterró con alguna «precipitación», y no de la manera más adecuada, pues se quería asegurar la posesión del santo cuerpo en Alba de Tormes, como dice Ana de San Bartolomé ${ }^{14}$. Pero San José de Ávila presentó su derecho por la posesión del santo cuerpo. Estaba claro que la madre Teresa en su último viaje fundacional quería y deseaba cuanto antes ir a Ávila, y era su deber hacerlo como priora de la comunidad abulense.

Por la decisión de los superiores de la Orden ${ }^{15}$ el 25 de noviembre de 1585 el santo cuerpo fue llevado a San José de Ávila; sin embargo, tuvo que ser devuelto a Alba de Tormes el 23 de agosto de 1586. En los años 1586-1588 surgió un pleito entre San José de Ávila y el convento de la Encarnación de Alba de Tormes, juntamente con la casa ducal de Alba ${ }^{16}$; el pleito terminó con sentencia

13 ANA DE SAN BARTOLOMÉ, Meditaciones 2, 6.

14 ANA DE SAN BARTOLOMÉ, Últimos años 2, 29: «Pusieron su cuerpo en un ataúd; cargaron sobre él tanta piedra, cal y ladrillo, que se quebró el ataúd y se entró dentro todo esto. Hizo esto la que dotó aquella casa, que se llamaba Teresa de Láiz, no bastando nadie a estorbárselo, pareciéndole que por cargar tanto de esto la tendría más segura que no se la sacasen de allí». Véase también en Declaración de 1587 22; Noticias 1, 20.

15 Cfr. doc. 28 (27-X-1585), en J. L. Astigarraga, E. Pacho y O. RodrígueZ, Fuentes históricas sobre la muerte y el cuerpo de santa Teresa de fesús (1582-1596), Roma, 1982 (MHCT, 6).

16 Cfr. MHCT 6, pp. 245-495. 
favorable a Alba de Tormes, con fecha de 1 de diciembre de $1588^{17}$, confirmada por el Breve de Sixto V el 10 de julio de $1589^{18}$. El poder de la casa ducal de Alba se hizo sentir.

\section{EL LARGO ITINERARIO HASTA LA BEATIFICACIÓN (1591-1614)}

Será difícil encontrar procesos de beatificación y canonización de la magnitud y extensión como los de la madre Teresa: conocemos a unos 769 testigos que declararon de un total de 41 procesos conservados; a estos habría que añadir al menos otros 17 perdidos (algunos de ellos importantes y extensos), con los que los testigos en su totalidad pasarían del millar (en un total de unos 60 procesos). Esto supone una muy extensa expansión de la fama de santidad y milagros de la Madre.

\section{Procesos informativos (1591-1597)}

Es considerable la importancia y magnitud de estos primeros procesos, llamados procesos informativos, en los que declararon 181 testigos: 122 eran mujeres y 59 hombres. Entre las mujeres 104 eran religiosas (101 carmelitas descalzas, 1 carmelita calzada, y 2 de la Tercera Orden regular de San Francisco). Entre los hombres había 23 religiosos (1 carmelita descalzo, 6 dominicos, 9 jesuitas, 6 carmelitas calzados y 1 jerónimo), 13 sacerdotes seculares y 23 seglares.

Se hicieron 18 procesos en otros tantos lugares: Salamanca y Alba, Ávila, Madrid, Toledo, Segovia, Huete, Zaragoza, Valladolid, Sevilla y Sanlúcar la Mayor, Lisboa, Valencia, Cuerva, Malagón, Piedrahita, Medina del Campo, Villanueva de la Jara.

a) Procesos informativos de Salamanca y Alba de Tormes (1591-1592, 1597)

Después de la muerte de la madre Teresa se extendió su fama de santidad, y sobre todo los milagros o cosas admirables que ocurrían en su nombre hacían que ella luciera de manera extraordinaria; además sus escritos también eran leídos

17 Cfr. MHCT 6, doc. 120 (pp. 490-492).

18 Cfr. MHCT 6, doc. 121 (pp. 492-495). 
con gran aprovechamiento. Y así don Jerónimo Manrique, obispo de Salamanca, mandó recibir información ex officio sobre la vida y milagros de la madre Teresa de Jesús; y lo hacía con fecha de 15 de octubre de $1591^{19}$.

En este documento se daban razones para tal determinación: había hechos que corroboraban su fama de santidad: su cuerpo había quedado incorrupto y Dios había «obrado maravillas en él»; mientras vivió «hizo santa y ejemplar vida, es reputado y tenido dentro y fuera de su religión por cuerpo santo, y con él hay particular devoción». Por lo tanto, ante estas obras, y para que no se olvidasen las maravillas que Dios obraba por medio de la Madre y las gracias que cada día recibían los fieles, era conveniente hacer en su diócesis la «información ad perpetuam rei memoriam, de la vida, acciones y milagros» de Teresa. El documento estaba acompañado por las preguntas, según las cuales habían de ser examinados los testigos.

El mismo obispo don Jerónimo presidió las declaraciones de los testigos, y el licenciado Juan Casquer fue el notario del proceso. En Salamanca declararon 13 testigos, y en Alba de Tormes 1920. El primero en declarar fue el teólogo dominico Domingo Báñez (en Salamanca: 16-X-1591), y el último fue el sacerdote Antonio de la Trinidad (en Alba de Tormes: 10-IV-1592).

b) Los demás procesos informativos (1595-1597)

Después de los dos procesos realizados el conocimiento de la fama de santidad de vida y milagros de la madre Teresa iba creciendo; las maravillas contadas sobre su cuerpo incorrupto se extendían por las más diversas ciudades y poblaciones. Así, tres años más tarde, el nuncio de Su Santidad en Madrid, Camilo Caetano, por deseo del rey Felipe II, decidió reemprender los procesos que había llevado a cabo el obispo de Salamanca, Jerónimo Manrique; así el nuncio, con fecha de 19 de mayo de 1595, nombró los jueces delegados suyos para que se instruyeran los procesos informativos en 16 diferentes poblaciones. Todas estas informaciones se llevaron a cabo en los años 1595-1597.

El nuncio mandó «al doctor Bernabé del Mármol, protonotario apostólico, que ad perpetuam rei memoriam recibiese información de la vida y acciones de la dicha madre Teresa de Jesús y de los milagros que nuestro Señor ha sido servido

19 Cfr. Procesos..., t. I, pp. 35-37.

20 No contabilizamos la declaración de Ana de Jesús, que tuvo lugar en 1597 dentro del programa de informaciones promovidas por el Nuncio Camilo Caetano. 
obrar por medio de su cuerpo»; a continuación iba el cuestionario del doctor Bernabé, según el cual debían ser interrogados los testigos ${ }^{21}$.

Pero fueron diversos los doctores que llevaron a cabo las informaciones: en Ávila se encomendaría el proceso al doctor Pedro de Tablares, «arcediano en la santa iglesia de Ávila»; en Madrid lo llevaron a cabo el mismo doctor Bernabé del Mármol Zapata y su hermano Juan Vázquez; en Toledo se encomendó al doctor Francisco de Almunia, «capellán de la Compañía de los Reyes Nuevos de Toledo»; en Segovia al doctor Luis Cabeza de Villegas, «canónigo de la penitenciaría de la santa iglesia de Segovia»; en Huete a Rodrigo del Castillo, «presbítero vicario del arcipreste de Huete»; en Zaragoza al doctor Gabriel de Sora, «canónigo de la santa iglesia metropolitana de Zaragoza»; en Valladolid al doctor Francisco Sobrino, «canónigo en la santa iglesia de Valladolid y catedrático de vísperas de teología»; en Sevilla al doctor Juan Hurtado, «canónigo de la santa iglesia de Sevilla», y en Sanlúcar la Mayor a don Luis Ponce de León, «canónigo en la santa iglesia de Sevilla, juez subdelegado por el doctor Juan Hurtado»; en Lisboa la información fue llevada a cabo por «el señor patriarca de Jerusalén, juez apostólico, ante Mauricio de Castro, notario, de la vida y milagros de la dicha venerable virgen Teresa de Jesús»; en Cuerva al doctor Francisco de Almunia, «capellán de la capilla de los Reyes Nuevos de la santa iglesia de Toledo», quien a su vez comisiona al doctor Alonso de Alcocer, «cura de la villa de Cuerva»; en Malagón al doctor Francisco de Almunia, quien a su vez comisiona al «licenciado frei Fernando González, rector y cura propio de la parroquial de Santa María» de la villa de Daimiel; en Piedrahita a don Pedro de Salazar Rengijo, «arcipreste de la dicha villa y su arciprestazgo, comisario del Santo Oficio de la Santa Inquisición del distrito de Valladolid»; en Medina del Campo al doctor Bernardino Vélez, «vicario juez de comisión susodicho»; en Villanueva de la Jara al licenciado Pedro de Vilches, «cura de la villa de Montilla» ${ }^{22}$; en Salamanca, para recibir la declaración de Ana de Jesús (Lobera), al maestro Juan Alonso Curiel, «catedrático de escritura en la universidad de la ciudad de Salamanca, canónigo en la santa iglesia catedral de la dicha ciudad ${ }^{23}$; y en Valencia ${ }^{24}$ al doctor Alonso de Ávalos.

El protonotario apostólico doctor Bernabé del Mármol Zapata, se responsabilizó de la ejecución del mandato del nuncio; él presentó el interrogatorio con

21 Procesos..., t. I, pp. 277-778.

22 Procesos..., t. I, véanse respectivamente las pp. 277, 394-528, 531, 577, 641, 660, 801, 867, 921, 935, 993, 995, 1015-1017, 1040-1041, 1053, 1078.

23 Procesos..., t. I, p. 245.

24 No consta con claridad. Con el tercer testigo se dice que «el doctor Alonso de Ávalos, comisario apostólico, mandó llamar al padre maestro Miguel de Carranza», tercer testigo: cfr. t. I, p. 974. 
diez preguntas, y fue él mismo el que, reunidos los procesos, esto es, sus correspondientes copias notariales, los presentó personalmente en Roma; de ello daba fe Felipe II en carta de 31 de marzo de 1597 (1598? $)^{25}$.

\section{Procesos remisoriales «in genere» (1604)}

El clamor por la canonización de la madre Teresa era patente. Así el reino de Castilla escribía al Papa en febrero de 1596 se sirviese «de la colocar en el número de los gloriosos santos» y don Fernando de Toledo gran prior de la Orden de San Juan, había dejado «hacienda bastante» para hacer los procesos necesarios, y convenía hacerlos antes de que murieran los muchos testigos de su santidad y milagros, y pedía que se lo encomendara al obispo de Ávila ${ }^{26} .11$ días antes Felipe II había comunicado a su embajador ante la Santa Sede, duque de Sessa, procurase «que su Santidad se sirva de mandar hacer la información que se suele, para comenzar y pasar adelante en su canonización» ${ }^{27}$.

$\mathrm{Al}$ año siguiente las iglesias metropolitanas y catedrales de los reinos de Castilla y León reincidían en la misma idea rogando inscribir a la madre Teresa entre las santas vírgenes ${ }^{28}$.

En 1600 El duque de Lerma instará al embajador de España ante la Santa Sede «poner el mayor calor que fuera posible» ante el Pontífice en el asunto de la canonización de la madre Teresa ${ }^{29}$. Y al año siguiente le escribirá sobre «la gran devoción que todos la tienen y deseo de verla canonizada. Y así se suplica a Su Santidad tenga por bien de conceder las remisorias para hacer la información antes que se acaben los testigos que la conocieron $\gg^{30}$. Por estas fechas el

25 Cfr. Procesos..., t. VI, p. 21, 769.

26 Cfr. Procesos..., t. II, p. 23 (23-II-1596).

27 Cfr. Procesos..., t. VI, pp. 765-766 (12-II-1596).

28 Cfr. Procesos..., t. II, pp. 24-26 (23-II-1596). Con la misma fecha el Reino de Castilla comunicaba al duque de Sessa la conveniencia «que su Santidad mande cometer en estos reinos algún prelado o prelados de ellos el examen de los testigos de la vida y muerte de la madre Teresa de Jesús y de los milagros» (t. VI, pp. 766-767). Con la misma fecha escribía también Fray Diego de Jesús al duque de Sessa diciendo cómo el Rey y los procuradores de Cortes habían escrito al papa suplicándole se hiciese «jurídica información de la vida ejemplar y santas costumbres de la madre Teresa de Jesús» (t. VI, pp. 767-768).

29 Cfr. Procesos..., t. VI, p. 770 (23-II-1600).

30 Cfr. Procesos..., t. VI, p. 772 (15-X-1601). Cuatro meses antes también María, emperatriz, escribía al embajador español ante la Santa Sede, que favoreciese los procesos necesarios para la canonización de la madre Teresa: t. VI, p. 771 (4-VI-1601). 
duque de Lerma se dirigió al papa Clemente VIII: «es muy grande la devoción que todos la tienen y el deseo de verla canonizada, y yo particularmente. Y así en nombre de todos suplico a Vuestra Santidad sea servido de conceder las remisorias para hacer la información antes que del todo se acaben los testigos que la conocieron» ${ }^{31}$.

En 1602 Felipe III pedía que concediese «remisorias para que en la forma acostumbrada se hagan las probanzas de su vida y milagros». $\mathrm{Y}$ al año siguiente en el mismo sentido se dirigía la Reina al Pontífice ${ }^{32}$.

Hacia estas fechas, especialmente en el año de 1602, a estas peticiones al Sumo Pontífice seguirá un aluvión de ellas de gran parte de instituciones sociopolíticas y religiosas de España y su entorno socio-político: Bernardo Sandoval y Rojas, cardenal de Toledo ${ }^{33}$; los arzobispos de México, García de Santa María y Mendoza, de Burgos, Antonio Zapata y Cisneros, de Valencia, Juan de Ribera y de Zaragoza Alfonso Gregorio; el arzobispo y el concilio provincial de Tarragona $^{34}$; los obispos de Córdoba, Francisco Reinoso, de Tuy, Francisco Terrones Aguilar del Caño, de Ciudad Rodrigo, Martín de Salvatierra, de Valladolid, Juan Bautista de Acebedo, de Salamanca, Pedro Junco y Posada, de Coria, Pedro García de Galarza, de Mondoñedo, Diego de Samaniego, de Osma, Pedro de Rojas, de Palencia, Martín de Axpe Sierra, de Lugo, Pedro de Castro y Nero, de Ávila, Lorenzo Otaduy y Avendaño, de Segovia, Diego de Soria y de Tarazona, Diego de Yepes $^{35}$. Y otras instituciones eclesiásticas y civiles y autoridades públicas como las iglesias metropolitanas y catedrales de los reinos de Castilla y León, diputados del reino de Aragón ${ }^{36}$; las ciudades de Ávila y de Lisboa ${ }^{37}$; el Capítulo de la iglesia de Ávila ${ }^{38}$; las universidades de Alcalá y de Salamanca ${ }^{39}$; el Duque de Alba (Antonio Álvarez de Toledo y Beamonte), Pedro Franquesa y Esteve, secretario del rey, Juan Fernández de Velasco, condestable de Castilla, el duque de Lerma

31 Cfr. Procesos..., t. VI, pp. 772-773 (X-1600).

32 Cfr. Procesos..., t. VI, pp. 26-27 (15-V-1602); pp. 27-28 (13-III-1603).

33 Cfr. Procesos..., t. VI, p. 65 (19-XI-1601); pp. 28-29 (25-V-1602).

34 Cfr. Procesos..., t. VI, pp. 30-31 (10-IV-1602), pp. 31-33 (29-IV-1602), pp. 29-30 (20-VI-1602), p. 33 (16-VII-1602), pp. 57-58 (2-II-1602).

35 Cfr. Procesos..., t. VI, pp. $48-49$ (17-VIII-1601), pp. 39-40 (27-XI-1601), p. 44 (29-I-1602), p. 34 (27-II-1602), p. 35 (10-III-1602), p. 36 (7-IV-1602), p. 40 (8-IV-1602), pp. 44-45 11-V-1602), pp. 44-45 (11-V-1602), pp. 36-37 (15-V-1602), pp. 37-38 (8-VII-1602), pp. 41-42 (21-VIII1602), pp. 42-43 (30-XI-1602), pp. 45-48 (5-V-1603).

36 Cfr. Procesos..., t. VI, pp. 49-51 (1602), pp. 51-53 (7-IV-1602).

37 Cfr. Procesos..., t. VI, pp. 53-54 (21-VIII-1602), pp. 54-55.

38 Cfr. Procesos..., t. VI, p. 56 (23-VIII-1602).

39 Cfr. Procesos..., t. VI, pp. 58-60 (1601), pp. 61-62 (2-II-1602). 
(Francisco Gómez de Sandoval Rojas) ${ }^{40}$; Dominicus Ginnasi, nuncio apostólico en España ${ }^{41}$.

A estas peticiones fueron añadidos algunos memoriales, uno era del rey de España ${ }^{42}$. También el P. Pedro de la Madre de Dios, comisario general de la Orden de los Carmelitas Descalzos de la Congregación de Italia escribió a Paulo Mucancio, secretario de la Congregación de Ritos en favor de la canonización de la madre Teresa de Jesús, juntamente con la súplica del padre general del Carmelo español y sus definidores ${ }^{43}$.

Atendiendo a tantas súplicas y el deseo general de las gentes de España para que se canonizase a la madre Teresa, el Duque de Lerma suplicó al Papa «con toda la instancia» que mandase «despachar segundas remisorias para su canonización» ${ }^{44}$. Y ocho meses más tarde volverá a pedir al Pontífice que le hiciese la «merced de favorecer la canonización» ${ }^{45}$.

Por fin, en 1604 se dio un paso importante. La sagrada congregación de Ritos se puso en marcha. En la primera reunión de esta congregación, el 7 de enero, se habló sobre la concesión de las cartas remisoriales in genere ${ }^{46}$. Estas se darían para los obispos de Ávila y Salamanca el 8 de mayo de $1604^{47}$.

Y el P. General, Francisco de la Madre de Dios, daba poderes al P. Tomás de Jesús para ejercer de «procurador general en los reinos de España de la canonización», $\mathrm{y}$ «hacer general inquisición de la fama y de la santidad de la dicha madre Teresa de Jesús» ${ }^{48}$.

El acto de la presentación de las letras apostólicas y del poder del procurador en Ávila tuvo lugar el 7 de agosto. Las 12 declaraciones las presidió el obispo de Ávila, Lorenzo Otaduy y Avendaño; ejerció de notario Francisco Fernández de León. La primera declaración se hizo el 7 de agosto de 1604, y la última el 12 del mismo mes. Y este mismo día 12 se cerraba el proceso. Al proceso se añadía una carta del obispo de Ávila para los cardenales de la Congregación de Ritos, comunicando el cumplimiento de la tarea encomendada de «hacer examen y la

40 Cfr. Procesos..., t. VI, pp. 58-60 (1601), pp. 61-62 (2-II-1602), pp. 62-63 (12-III-1602), pp. 63-64 (1-V-1603), p. 67 (1-XII-1601), pp. 67-68 (15-XII-1601).

41 Cfr. Procesos..., t. VI, pp. 65-66 (26-VIII-1602).

42 Cfr. Procesos..., t. VI, p. 68.

43 Cfr. Procesos..., t. VI, pp. 75-77 (25-VII-1602).

44 Cfr. Procesos..., t. VI, p. 777 (8-III-1603).

45 Cfr. Procesos..., t. VI, pp. 780-781 (6-XI-1603).

46 Cfr. Procesos..., t. VI, pp. 78-79 (7-II-1604).

47 Cfr. Procesos..., t. VI, pp. 83-86; t. II, pp. 18-19.

48 Cfr. Procesos..., t. II, pp. 20-21. 
probanza» sobre la fama de santidad y milagros de la madre Teresa de Jesús con pocos testigos, $\ll$ por excusar prolijidad ${ }^{49}$.

En Salamanca las letras apostólicas y el poder del procurador se presentaron el 18 de agosto. Procurador de la Orden era el padre Tomás de Jesús, y Juan García Rodríguez ejerció de notario ${ }^{50}$. Todas las declaraciones fueron presididas por don Luis Fernández de Córdoba, obispo de Salamanca. La primera declaración tuvo lugar ese mismo día 18 y la última el día 21 de agosto.

\section{Procesos remisoriales «in specie» (1609-1610)}

En la $4^{\text {a }}$ reunión de la Congregación de Ritos, de 16 de julio de 1605, se leyó el memorial del Rey Católico y se presentaron los procesos de Ávila y Salaman$\mathrm{ca}^{51}$. Y el 12 de noviembre del mismo año en la $6^{\mathrm{a}}$ reunión de la Congregación se presentaron estos procesos ya traducidos al italiano ${ }^{52}$.

En la $8^{\text {a }}$ reunión, de 28 de enero de 1606, se relató sobre el contenido de los procesos, haciendo un compendio de la vida y milagros de la madre Teresa ${ }^{53}$. Tanto el embajador de España ante la Santa Sede, el marqués de Villena, como el P. Pedro de la Madre de Dios, procurador de la causa de canonización, presentaron memoriales ${ }^{54}$.

El 16 de enero de 1607 en la $10^{\text {a }}$ reunión de la Congregación, el cardenal Pamphilli hizo relación sobre los procesos in genere, y mostró que se habían llevado a cabo bien y correctamente, y la congregación era favorable a expedir las letras remisoriales in specie ${ }^{55}$.

Mientras tanto el 2 de marzo de 1607, el Rey Católico insistía en que se expidieran «letras remisorias para las segundas informaciones de la canonización de la madre Teresa de Jesús, y que en el ínterin que esto se efectúa, se beatifique como más largamente lo dirá a Vuestra Santidad el marqués» ${ }^{56}$. El Capítulo general de los Carmelitas Descalzos de España se sumaba a estas peticiones ${ }^{57}$.

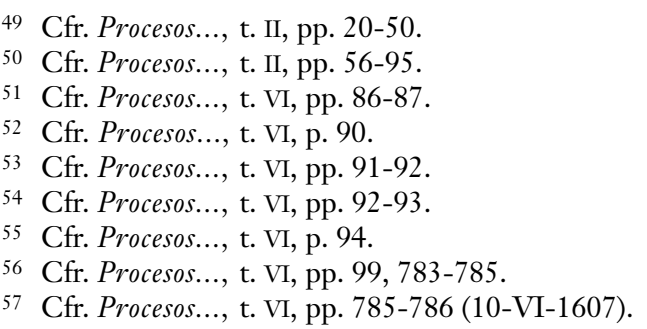


Algunos meses después Margarita, reina de España, suplicaba al papa Paulo V en este mismo sentido, y le añadía: «Y porque el marqués de Aitona hablará más largamente en esta materia a Vuestra Santidad de mi parte, le suplico le dé entera fe y crédito, y a mí me haga en ella la gracia que espero de Vuestra Beatitud, mandando se beatifique su cuerpo, y se rece de ella en su religión, mientras se trata y verifica lo que toca a su canonización; que toda la que Vuestra Santidad me hiciere en esto, será para mí de particular estimación» ${ }^{58}$.

$\mathrm{Al}$ año siguiente también el rey de Polonia, Segismundo III, pedía al Papa la canonización de la Madre Teresa de Jesús ${ }^{59}$.

Por fin, el 27 de septiembre de 1608 se expedían las Letras apostólicas de los cardenales de la Congregación de Ritos al cardenal de Toledo para que se iniciase el proceso remisorial in specie para la beatificación de la madre Teresa ${ }^{60}$. Se enviaba también el Rótulo con las 117 cuestiones por las que debían ser examinados los testigos ${ }^{61}$.

El orden cronológico de los procesos es, según la primera declaración de cada proceso, el siguiente: Madrid (la primera declaración el 13 de octubre de 1609, y la última el diez de septiembre del año siguiente); presidió este proceso el obispo Lucas Durán, obispo de Chiapa; y ejerció de notario público apostólico Francisco Ortiz de Salcedo. Salamanca-Alba (17 de febrero de 1610: declaración del agustino Diego de Guevara; y la última el 18 de septiembre del mismo año por el carmelita Blas de San Alberto); ejerció de notario apostólico Juan García Rodríguez Beltrán. Roma (primera declaración el 10-III-1610, la última el 25V-1610). Burgos (primera declaración el 12 de junio de 1610 y la última el día 5 del mes siguiente). Ávila (primera declaración el 23 de junio de 1610, la última, que fue de Luisa de Vera Guzmán, el 23 de septiembre del mismo año); y ejerció de notario público apostólico Antonio de Ayala. Valladolid (las declaraciones comenzaron el 30 de julio de 1610 y terminaron el quince de septiembre); ejerció de notario Lucas Martínez Araujo. Alcalá de Henares (la primera declaración el 3 (?) de agosto de 1610 y la última el 17 de agosto); hizo de notario Hernando de Atienza. Cuenca y Valera (la primera declaración tuvo lugar el 3 de agosto de 1610, y la última el 27 del mismo mes); ejerció de notario Agustín Martínez. Málaga (el 25 de agosto de 1610, y terminaron pocos días después, el 4 de septiembre), ejerció de notario Juan Peralta de la Serna. Villanueva de la Jara (comenza-

\footnotetext{
58 Cfr. Procesos..., t. VI, p. 787 (11-XI-1607).

59 Cfr. Procesos..., t. VI, pp. 125-126 (17-IV-1608).

60 Cfr. Procesos..., t. II, pp. 99-105; t. VI, pp. 115-120.

61 Cfr. Procesos..., t. VI, pp. 112-115; t. II, pp. 106-261.
} 
ron las declaraciones el 30 de agosto de 1610 y terminaron el 2 de septiembre); ejerció de notario Agustín Martínez.

Todos estos procesos se llevaron a cabo en 1610; sólo las declaraciones de Madrid comenzaron el 13 de octubre de 1609, pero terminaron el 10-IX-1610.

Los procesos son desiguales en su magnitud; los más extensos son los de Ávila, Salamanca, Alba y Madrid; después los de Valladolid y Burgos, y todavía en menor medida los de Villanueva de la Jara, Cuenca, Valera, Málaga, Alcalá de Henares y Roma.

Llama la atención la cantidad de procesos. Se han conocido y publicado 12 procesos. Sin embargo, al menos otros 17 se han perdido; de algunos se han conservados sólo fragmentos.

Los procesos que se han perdido corresponden a los de las ciudades siguientes: Medina del Campo, Segovia, Toledo, Malagón, Granada, Zaragoza, Talavera de la Reina, Consuegra, Ocaña, Tarazona, Yepes, Cuerva, Daimiel, Santo Domingo de la Calzada, Arenas y Alfaro. Y además en Flandes hubo probablemente más de uno.

Esto implica una gran expansión de fama que tenía la Madre Teresa en el primer decenio del siglo XVII, el conocimiento que se tenía de ella, y muy en particular las maravillas que las gentes veían que hacía la Madre Teresa..., la fama de sus milagros, de sus manuscritos, especialmente trozos de cartas suyas autógrafas, que eran tan requeridas... Todo esto explica que se hicieran procesos en unas 30 ciudades; esto es, sólo respecto a los procesos remisoriales «in specie». Pero su fama era conocida en gran parte de Europa y en América latina.

\section{Beatificación (1614)}

En la reunión de la Congregación de Ritos el 25 de junio de 1611 fueron presentados los procesos enviados de España y se determinó que fueran traducidos al latín. Se mencionaban los procesos de Madrid, Zaragoza, Segovia, Alcalá de Henares, Granada, Medina del Campo, Talavera de la Reina, Cuenca, Burgos, Málaga, Valladolid, y Tarazona ${ }^{62}$. En la de 19 de noviembre del mismo año se leyeron las cartas de los soberanos de Flandes, Alberto e Isabel, quienes pedían al Pontífice no diferir más tiempo la canonización de la madre Teresa ${ }^{63}$.

En la reunión del 14 de enero de 1612 se presentaron y se leyeron muchas cartas que pedían ya la beatificación y canonización de la madre Teresa: con la fi-

62 Cfr. Procesos..., t. VI, pp. 139-140.

63 Cfr. Procesos..., t. VI, p. 142. 
nalización de los procesos y envío de ellos a Roma el rey Felipe III aprovechaba el 27 de diciembre de 1610 para suplicar con «el encarecimiento posible» que se llevase a cabo «este negocio» ${ }^{64}$. Cinco días antes lo había hecho la reina Margarita ${ }^{65}$.

Entre las muchas peticiones al Papa se hallaban las de: los arzobispos de Tarragona, Compostela, Granada, Burgos y Lisboa ${ }^{66}$; los obispos de Burgo de Osma, Palencia, Pamplona, Zamora, Ciudad Rodrigo, Córdoba, Tarazona, Calahorra, Jaén, Coria, Valladolid, Plasencia, Huesca, Tortosa, Urgel, Barbastro, Málaga, Salamanca, Lerida, Albarracín y Barcelona ${ }^{67}$; los capítulos catedrales de Ciudad Rodrigo, Évora, Plasencia, Burgo de Osma, Valladolid, Burgos y Salamanca ${ }^{68}$; las ciudades de Coria, Tarragona, Logroño, Lisboa, Ciudad Rodrigo, Coria, Vitoria, Sevilla, Córdoba, Soria, Tortosa, Jaén, Salamanca, Valladolid, Calatayud, Santo Domingo de la Calzada, Évora, Plasencia, Málaga, Zaragoza, Burgos, Granada, Palencia, Elba, Barcelona, Valencia y Ávila ${ }^{69}$; las de otras autoridades e instituciones civiles: como el reino de Castilla, el reino de Aragón, el señorío de Bizkaia, la universidad de Salamanca y la de Coimbra ${ }^{70}$.

64 Cfr. Procesos..., t. VI, pp. 143-144.

65 Cfr. Procesos..., t. VI, pp. 144-145: ... «que muestra bien la santidad de su fundadora, la beata madre Teresa de Jesús, y como quiera que su vida está tan calificada con sus milagros y santos libros, siendo hija de estos reinos, y yo tan obligada del amor y afición que me tienen y de la devoción de estos religiosos, es fuerza que corra por mi cuenta la solicitud de su canonización, suplico a Vuestra Santidad con la humildad que puedo se sirva de abreviarla cuanto sea posible, para que todos entiendan las veras con que he tomado a mi cargo esta diligencia, que recibiré en ello muy grata complacencia de Vuestra Santidad».

66 Cfr. Procesos..., t. VI, pp. 147-148 (12-IV-1611), pp. 146-147 (20-IV-1611), pp. 159-161 (25-IV1611), p. 159 (10-V-1611), pp. 161-162 (29-V-1611).

67 Cfr. Procesos..., t. VI, pp. 168-169 (4-IV-1611), pp. 169-170 (IV-1611), pp. 152-153 (8-IV-1611), p. 151 (18-IV-1611), p. 174 (19-IV-1611), pp. 148-150 (20-IV-1611), pp. 150-151 (20-IV-1611), pp. 166-167 (22-IV-1611), pp. 163-164 (25-IV-1611), pp. 171-172 (26-IV-1611), p. 173 (28-IV1611), p. 165 (29-IV-1611), pp. 177-178 (29-IV-1611), pp. 162-163 (30-IV-1611), p. 177 (30-IV1611), pp. 178-179 (6-V-1611), pp. 165-166 (8-V-1611), pp. 170-171 (13-V-1611), pp. 175-176 (25-V-1611), pp. 179-180(27-V-1611), p. 175 (16-VIII-1611).

68 Cfr. Procesos..., t. VI, pp. 188-189 (18-IV-1611), pp. 181-182 (IV-1611), pp. 182-183 (29-IV-1611), p. 183 (4-V-1611), pp. 185-187 (12-V-1611), pp. 180-181 (19-V-1611), pp. 184-185 (14-VI-1611).

69 Cfr. Procesos..., t. VI, pp. 187-188 (2-IV-1611), pp. 215-216 (13-IV-1611), pp. 199-200 (15IV-1611), pp. 212-213 (19-IV-1611), pp. 195-196 (20-IV-1611), pp. 193-194 (21-IV-1611), pp. 198-199 (22-IV-1611), pp. 213-214 (22-IV-1611), pp. 214-215 (22-IV-1611), pp. 196-197 (26-IV-1611), pp. 204-205 (26-IV-1611), pp. 207-208 (26-IV-1611), pp. 191-192 (27-IV-1611), pp. 190-191 (29-IV-1611), pp. 201-202 (30-IV-1611), pp. 197-198 (30-IV-1611), pp. 209-210 (30-IV-1611), pp. 192-193 (1-V-1611), pp. 206-207 (7-V-1611), pp. 200-201 (10-V-1611), pp. 189-190 (12-V-1611), pp. 205-206 (22-V-1611), pp. 194-195 (24-V-1611), p. 210 (31-V1611), pp. 203-204 (6-VI-1611), pp. 202-203 (21-VI-1611), 155-156 (6-VII-1611).

70 Cfr. Procesos..., t. VI, pp. 211-212 (2-II-1611) y 153-154 (2-V-1611), pp. 154-155 (11-V-1611), pp. 156-157 (24-IV-1611), pp. 157-158 (13-VI-1611), pp. 208-209 (IX-1611). 
A todas estas peticiones habría que añadir la de Segismundo III, rey de Polonia, con fecha de 28 de noviembre de $1611^{71}$.

El 7 de julio de 1612 en la 23 $3^{\text {a }}$ reunión de la Congregación de Ritos se leyó una instancia y memorial del Rey Católico para que se beatificara a la madre Teresa «con toda la brevedad posible», y se pedía se remitiesen los procesos a algunos de los cardenales para que los viese ad effectum beatificationis; y otro tanto hacía la Orden de los Carmelitas Descalzos ${ }^{72}$ : se encargó al cardenal Lancellotti ${ }^{73}$.

En septiembre Alejandro Falciano, procurador de la causa, presentó al cardenal Lancelloto las «informationes facti et iuris», exponiendo la corrección y legalidad con que habían sido llevados a cabo los procesos ${ }^{74}$. Iba también el Summarium de las deposiciones de los testigos acerca de las virtudes heroicas y santidad de vida de la sierva de Dios Teresa de Jesús ${ }^{75}$.

En la 24a reunión de la Congregación, de 12 de noviembre de 1612, los cardenales aprobaron los procesos, pues habían sido llevados a cabo con todas las garantías jurídicas necesarias ${ }^{76}$. Y al mes siguiente, el día 22, en la $25^{a}$ reunión de la Congregación los cardenales declaraban que la heroicidad de las virtudes y de la santidad de vida de la sierva de Dios estaban totalmente demostradas, y así se lo comunicaba el cardenal Lancellotti al papa ${ }^{77}$.

El 19 de enero de 1613 en la reunión se determina que los cardenales Del Monte y Lancellotti diesen cuenta al Papa de la situación y poder ir adelante en esta causa ${ }^{78}$. Quedaba por examinar en la Rota los milagros de la sierva de Dios ${ }^{79}$; el examen sería llevado a cabo por tres auditores de la Rota ${ }^{80}$.

En la $27^{\mathrm{a}}$ reunión de la Congregación, el 16 de noviembre de 1613 se presentó la relación de los tres auditores, Francisco Sacrati, Giovanni Battista Coccini y Alfonso Manzanedo de Quiñones, sobre los milagros y la beatificación de la sierva de Dios Teresa de Jesús; según el resultado positivo del examen de los procesos sobre su vida y santidad y milagros se podía proceder a la beatificación y canonización ${ }^{81}$.

71 Cfr. Procesos..., t. VI, p. 789.

72 Cfr. Procesos..., t. VI, pp. 216-219.

73 Cfr. Procesos..., t. VI, p. 219.

74 Cfr. Procesos..., t. VI, pp. 224-242.

75 Cfr. Procesos..., t. VI, pp. 243-383, 384-400.

76 Cfr. Procesos..., t. VI, p. 402.

77 Cfr. Procesos..., t. VI, p. 402-403.

78 Cfr. Procesos..., t. VI, p. 403.

79 Cfr. Procesos..., t. VI, p. 403.

80 Cfr. Procesos..., t. VI, p. 403.

81 Cfr. Procesos..., t. VI, pp. 407-455. 
Y el 2 de enero de 1614 los tres auditores relatan al Papa sobre la constancia de la virtudes y excelente santidad de la sierva de Dios, y después del examen de los milagros, se hallan en la situación de poder proceder no sólo a la concesión de recitar el oficio y celebrar misas solemnes para toda la Orden de los Carmelitas Descalzos y los reinos de España, sino también proceder a la solemne canonización acostumbrada en la Iglesia ${ }^{82}$.

En las siguientes reuniones de los cardenales se examinaron algunos milagros, hasta que fue aprobado el último milagro, el duodécimo ${ }^{83}$. El 12 de abril de 1614 la Congregación decide la beatificación de Teresa de Jesús, y esta resolución es presentada dos días después al Papa, quien la aprueba ${ }^{84}$. Y el 14 se da el decreto de la Congregación de Ritos, aprobado por el Papa, sobre la beatificación ${ }^{85}$. El Breve de la beatificación, firmado por Paulo V, se dio el 24 de abril de $1614^{86}$.

Respecto a los libros y a la doctrina de la madre Teresa había habido de parte del dominico Juan de Lorenzana un recurso a la Inquisición contra algunos aspectos de la doctrina de la Madre ${ }^{87}$. Diego de Yepes le contestaba en 1594 en defensa de la madre Teresa ${ }^{88}$. Este hecho fue el origen de la posterior acusación hecha en Roma contra la doctrina teresiana.

Al llegar a Roma alguna censura contra su doctrina y libros, hubo que presentar la defensa de la doctrina teresiana y en contra de las acusaciones. Oficialmente la defensa fue presentada al papa por Diego Álvarez, arzobispo de Trani, y por Juan de Rada, obispo de Pati en Sicilia ${ }^{89}$.

De parte del Carmelo Teresiano hicieron una defensa adecuada tres teólogos: Tomás de Jesús ${ }^{90}$, Pedro de la Madre de Dios ${ }^{91}$, ambos en castellano, y Juan de Jesús María en latín ${ }^{92}$.

82 Cfr. Procesos..., t. VI, p. 456.

83 Cfr. Procesos..., t. VI, pp. 457-461.

84 Cfr. Procesos..., t. VI, p. 462.

85 Cfr. Procesos..., t. VI, pp. 463-466.

86 Cfr. Procesos..., t. VI, pp. 467-468.

87 Cfr. EnRIQue del S. CORAZÓn, Santa Teresa de fesús ante la Inquisición española, en Ephemerides Carmeliticae, 13 (1962), pp. 518-565; Enrique Llamas, Santa Teresa de Jesús y la Inquisición espanola, Madrid, 1972, pp. 352-392; Fortunato ANTOLÍN, Intervención de Diego de Yepes en favor de la doctrina teresiana, en Revista de Espiritualidad, 190 (1989), pp. 313-318.

88 Cfr. Procesos..., t. VI, pp. 797-799.

89 Cfr. Procesos..., t. VI, pp. 799-824.

90 Cfr. Procesos..., t. VI, pp. 825-878.

91 Cfr. Procesos..., t. VI, pp. 879-895.

92 Cfr. ARChivo GenERAL OCD, plút. 387 e. 


\section{LOS ÚLTIMOS PASOS HASTA LA CANONIZACIÓN (1614-1622)}

El 17 de junio de 1614 el rey de España agradecía al Papa la beatificación de la madre Teresa; y le añadía: «Y para que el consuelo y edificación de los fieles y devotos suyos sea mayor suplico a Vuestra Santidad, que pues ha dado principio a obra tan piadosa, la acabe en el felicísimo tiempo de su pontificado, mandando que se canonice tan ilustre y gloriosa santa, pues los frutos de sus obras y efectos de sus milagros son tan conocidos en el mundo ${ }^{93}$. Ocho días después con semejantes sentimientos de agradecimiento y súplica por la canonización le escribía también la ciudad de Ávila ${ }^{94}$; y dos días después lo haría el general de los Carmelitas Descalzos de la congregación española, José de Jesús María ${ }^{95}$.

El emperador Matías de Habsburgo escribía desde Viena al Papa, con fecha de 27 de enero de 1615, pidiendo la canonización de la madre Teresa ${ }^{96}$; otro tanto haría cuatro meses después, el 5 de junio, el reino de Castilla, recordándole «la alegría que ha causado en los ánimos de los fieles su beatificación $\gg^{97}$.

En diferentes reuniones de los primeros meses de 1615 se discutió sobre la vida y virtudes de la beata Teresa: los tres auditores de la Rota, Francisco Sacrati, Giovanni Battista Coccini y Alfonso Manzanedo de Quiñones, presentaron el estudio y se dio el juicio sobre la canonización a realizar ${ }^{98}$.

En la primera parte se analizan los procesos realizados tanto informativos como los remisoriales; y se confirma la validez de ellos ${ }^{99}$. En la segunda parte se expone la santidad de vida, y se intentaba explicar la santidad requerida para la canonización haciendo constar en la vida de la beata Teresa las virtudes, siempre ahondando en las declaraciones de testigos, que aparecen en los procesos: a) en tres artículos se expone la vitalidad de sus virtudes teologales, de fe, esperanza y caridad $^{100}$. Se dejaba constancia de la heroicidad con la que había practicado las tres virtudes teologales; b) en otros cuatro artículos se analizan las cuatro virtudes cardinales (prudencia, justicia, fortaleza y temperancia) ${ }^{101} ; \mathrm{c}$ ) después en los artículos 11-13 se constataba el modo heroico con que practicó los votos de obe-

\footnotetext{
93 Cfr. Procesos..., t. VI, p. 475.

94 Cfr. Procesos..., t. VI, pp. 477-478.

95 Cfr. Procesos..., t. VI, pp. 478-479.

96 Cfr. Procesos..., t. VI, pp. 486-487.

97 Cfr. Procesos..., t. VI, p. 487.

98 Cfr. Procesos..., t. VI, pp. 488-572.

99 Cfr. Procesos..., t. VI, pp. 491-496.

100 Cfr. Procesos..., t. VI, pp. 506-521.

101 Cfr. Procesos..., t. VI, pp. 521-530.
} 
diencia, castidad y pobreza; d) a continuación su vida de humildad, de paciencia, de penitencia, de mansedumbre, de magnanimidad, de gratitud ante Dios y los hombres ${ }^{102}$; e) también se examinaron los dones divinos recibidos y las gracias gratis datas: el don sublime de la oración y contemplación, de éxtasis, visiones y revelaciones ${ }^{103}$; el don de la profecía y discreción de espíritus, así como el don de sabiduría y ciencia, y el de curaciones, etc. ${ }^{104}$; f) en el artículo 23 se analizaron los dones del Espíritu Santo y sus frutos; y en el artículo 24 la fama y opinión de santidad que la beata Teresa tuvo en vida y después de muerta. Los tres auditores concluían recordando tantas súplicas dirigidas al Papa, entre las que se hallaban las de los reyes de España y Polonia, de los archiduques de Austria, de arzobispos y obispos, de instituciones políticas y culturales, que imploraban al Sumo Pontífice que la beata Teresa de Jesús fuera inscrita en el número de los santos ${ }^{105}$.

Efectivamente, no sólo el rey de España había hecho la petición al Papa, y lo mismo que los soberanos de Flandes Alberto e Isabel Clara Eugenia ${ }^{106}$, sino también el rey y la reina de Francia, y su hija Isabel con fecha de 31 de enero de $1615^{107}$.

El día 25 de mayo de 1617 fue un día significativo, cargado de gestos considerables: era día de Corpus Christi, y el Papa fue desde San Pedro a la iglesia carmelitana de la Scala; iba acompañado de más de 20 cardenales y muchos obispos: el Sumo Pontífice, después de hacer oración al Santísimo Sacramento, veneró la reliquia del pie de la beata Teresa, diciendo que merecía ser canonizada ${ }^{108}$.

El 17 de julio de 1617 la Congregación, habiendo hecho relación al Papa de lo decretado por dicha Congregación con satisfacción de todos, el Papa concedió a todos los reinos de España y a Portugal la gracia dada a Castilla la Vieja: que los religiosos y las religiosas y sacerdotes seculares pudieran rezar el oficio y decir misa de la beata Teresa en su día, el 5 de octubre ${ }^{109}$. Y días después, el 3 de agosto, se expidió el Breve de esta extensión de la gracia concedida ${ }^{110}$.

$\mathrm{Al}$ año siguiente, el 27 de mayo, el procurador general de la Orden dio al Papa una reliquia de la beata Teresa, enviada de España: era un pedazo de car-

\footnotetext{
102 Cfr. Procesos..., t. VI, pp. 531-553.

103 Cfr. Procesos..., t. VI, pp. 553-562.

104 Cfr. Procesos..., t. VI, pp. 562-569.

105 Cfr. Procesos..., t. VI, pp. 569-572.

106 Cfr. Procesos..., t. VI, pp. 598-602.

107 Cfr. Procesos..., t. VI, pp. 594-598.

108 Cfr. Un diario curioso de la canonización de Sta. Teresa, en Monte Carmelo, 27 (1923), p. 114.

109 Cfr. Procesos..., t. VI, p. 605.

110 Cfr. Procesos..., t. VI, pp. 605-607.
} 
ne, «adornado en una como custodia de plata, y un pedazo de lienzo o sábana bañado y manchado con el óleo que sale del santo cuerpo. Recibióla con grande alegría, y dijo que era la cosa de mayor gusto que le podían dar, que la estimaba grandemente» ${ }^{111}$.

El 13 de octubre de 1618, en la reunión de la Congregación de Ritos, se leyó un memorial que el Papa había enviado, en que se manifestaba lo bien que había sido recibida la gracia de la extensión a los reinos de España y cómo la habían hecho patrona de esos reinos ${ }^{112}$. Efectivamente, el 30 de noviembre de 1617 los reinos de Castilla y León habían decretado tener a la beata Teresa por su patrona y abogada ${ }^{113}$.

Después de sufrir dos ataques Paulo V murió el 28 de enero de 1621. El día 9 del mes siguiente Alejandro Ludovisi fue elegido Papa, que tomó el nombre de Gregorio XV. Pronto le llegaron muchas cartas de soberanos y cardenales pidiéndole que sin más demora canonizara a la beata Teresa de Jesús.

En julio de 1621 tuvo lugar la intensa y larga discusión sobre los procesos e informaciones realizadas en relación con la vida, virtudes y milagros de la beata Teresa en orden a la canonización ${ }^{114}$.

Al comienzo del documento se recordaba las insistentes peticiones llegadas de muchas partes a favor de la canonización de la beata, mencionando las cartas del emperador Fernando II, de los reyes de España y Francia, de los archiduques de Austria, Alberto e Isabel, y también de los cardenales Giovanni Garzia Millini, de Mauricio de Savoia, de Eduardo Farnesio... Y el 8 de julio de 1621 se presentaron al nuevo Papa, Gregorio XV, las duquesas de Alburquerque y de Fiano suplicándole que accediese a la canonización. El Pontífice respondió: «Tutto il mondo esclama per questa santa, veramente e grande la santa, non potiamo già più resistere, lo faremo, lo faremo» ${ }^{115}$.

También desde Flandes se insistió con fuerza. El procurador general de la Orden hacia junio de 1621 pedía al Archiduque Alberto cartas suplicando al Papa la canonización de la madre Teresa, y otro tanto pedía a la Infanta ${ }^{116}$.

El embajador de la corte de Bruselas ante la Santa Sede, Juan Bautista Vives, manifestaba personalmente al Papa la devoción de sus Altezas, que querían que

\footnotetext{
111 Cfr. Un diario curioso de la canonización de Sta. Teresa, en Monte Carmelo, 27 (1923), p. 207.

112 Cfr. Procesos..., t. VI, pp. 607-608.

113 Cfr. Procesos..., t. VI, pp. 613-616.

114 Cfr. Procesos..., t. VI, pp. 650-701.

115 Cfr. Procesos..., t. VI, p. 650.

116 Cfr. Procesos..., t. VI, pp. 792-793.
} 
Teresa fuera canonizada. El embajador le expresaba la calidad de Fundadora para que fuera canonizada. El Papa le contestaba extrañamente que Teresa no era fundadora sino reformadora. El embajador siguió insistiendo ${ }^{117}$. Los Archiduques respondían al embajador que insistiese en su empeño por la canonización ${ }^{118}$.

El P. Tomás de Jesús escribía una hermosa carta a la Infanta manifestándole la conveniencia de que ella hiciese de patrona de la canonización de la madre Teresa:

según nos escriben de Roma su majestad de España está ocupado en pedir la canonización del beato Isidro de Madrid; el rey de Francia en la del beato Ignacio; nuestra santa Madre está sola, que no tiene al presente ningún patrón de su canonización, que aunque es verdad escribirán su majestad y algunos Príncipes, pero falta quien tome este negocio y lo solicite con su Santidad como propio [...] que su Santidad entienda que no es cumplimiento el demandar la canonización de la santa, sino afición entrañable que vuestras altezas le tienen y deseo grande de ver premiada en la tierra la que Nuestro Señor tiene tan glorificada en el cielo; y no sólo con su Santidad, sino principalmente con el cardenal Ludovisio ${ }^{119}$, su sobrino, que es el todo en los negocios, se ha de hacer por el agente de vuestras altezas las mismas diligencias ${ }^{120}$.

El P. Tomás hizo la instancia oficial al Papa, recordando a la heroína del Antiguo Testamento, Judit; se pedía la glorificación de la madre Teresa ${ }^{121}$.

Hacia el 10 [?] de febrero de 1622 el embajador Juan Bautista Vives presentaría al Papa la carta de agradecimiento de la Infanta por haber decidido la canonización de la madre Teresa de Jesús ${ }^{122}$.

Por estas fechas también el rey de Polonia insistía: el 3 de enero de 1621 Segismundo III había escrito al cardenal Montalto ${ }^{123}$; y el último día de ese mismo

117 Cfr. ArChives GÉnÉrales du Royaume (Bruselas), Negotiations de Rome. Papiers d'État et de l'Audience, vol. 546, año 1621, ff. 135-136, fecha de 19-VII-1621.

118 Cfr. ARChIVES GÉNÉRALES DU RoYaume (BRUSElas), Negotiations de Rome. Papiers d'État et de l'Audience, vol. 546, año 1621, f. 151, fecha de 10-VII-1621.

${ }^{119}$ Ludovico Ludovisio, nombrador cardenal en el consistorio de 15-II-1621; nombrado obispo de Bologna (27-III-1621); siguió trabajando en la curia vaticana, murió el 18-XI-1632 (cfr. HC IV, pp.15-16, 118).

120 Cfr. Procesos..., t. VI, pp. 793-794.

$121 \ll$ Restat, Pr Sancte, [...] Virgo nostra titulo et honore quo sanctae virgines in cathalogo Ecclesiae Catholicae descriptae insigniri solent, $S^{\text {te }} V^{\text {ra }}$ panformiter decoretur. Quod servato ritu $\mathrm{Ecc}^{\text {ae }}$ Ser ${ }^{\text {mus }}$ Albertus Belgicarum Piissimus Princeps, per suam tabellam et per Jo. Baptistam Vives eius apud $\mathrm{S}^{\text {tem }} V^{\text {am }}$ oratorem suo tempore quam primum exegui ex corde optans instantes, instantius et instantissime supplex interpellat ac enixe supplicat» (cfr. t. VI, p. 795).

122 Cfr. ArChives GÉNÉRAles du Royaume (BRUselas): Negotiations de Rome. Papiers d'État et de l'Audience, vol. 458, año 1621, f. 50, fecha de 10(?)-II-1622).

123 Cfr. Procesos..., t. VI, pp. 790-791. 
año al papa Paulo $\mathrm{V}$ pidiendo la canonización ${ }^{124}$. Y tres días más tarde lo haría su hijo, el príncipe Vladislao Segismundo ${ }^{125}$.

El 4 de septiembre de 1621 se reunieron los miembros de la Congregación de Ritos; se presentó un memorial del padre procurador de la causa, y con el trabajo de los auditores de la Rota iba concluyendo la causa a efectos de la canonización; y los cardenales debían juzgar y declarar sobre los procesos y su validez, y en otra reunión sobre su vida y virtudes, y en una tercera sobre sobre sus milagros.

Conocemos los textos presentados, ordenados en tres partes, firmados por Melchor Ramírez. 1) Se analiza jurídicamente sobre la validez de los procesos remisoriales y compulsoriales. Se hace referencia a 25 procesos $^{126}$. 2) El 25 de septiembre de 1621 el cardenal Tiberio Muti hizo relación sobre la santidad de vida en general y en particular; y con admiración y aplauso de los cardenales se decretó la constancia de la santidad de vida, de las virtudes heroicas y dones de la beata Teresa ${ }^{127}$.3) En la reunión del 13 de noviembre del mismo año los cardenales juzgaron constar suficientemente los milagros realizados en vida y después de la muerte de la beata Teresa. Y decretaron que esta causa se hallaba en tal estado, que según el rito y los cánones de la santa Iglesia Romana, estaba en disposición (si satisfacía al Sumo Pontífice) de poder llevar a cabo la canonización y la adscripción en el número de los santos ${ }^{128}$. Se analizaron tres milagros realizados durante su vida, uno a su muerte, y doce después de su muerte.

El 22 de diciembre de 1621 la Congregación de Ritos resolvió y determinó llevar a cabo, si era del agrado del Sumo Pontífice, la canonización de cinco beatos (Isidro, Ignacio, Xavier, Teresa y Filipo) a la vez en un mismo día, e inscribirlos en el número de los santos. Este decreto no sólo fue aprobado por el Pontífice, sino además personalmente sentía por ello una gran alegría y una singular consolación $^{129}$.

El 24 de enero de 1622 tuvo lugar el consistorio secreto en el palacio apostólico, presidido por el papa Gregorio XVI; y el cardenal Francisco María Borbonio de Monte tuvo la «Relatio» de la santidad de vida y milagros de la beata Teresa de Jesús. Terminaba proponiendo, si era del agrado del Santo Pa-

\footnotetext{
${ }^{124}$ Cfr. Procesos..., t. VI, pp. 791-792.

125 Cfr. Procesos..., t. VI, pp. 793-794.

126 Cfr. Procesos..., t. VI, pp. 652-666.

127 Cfr. Procesos..., t. VI, pp. 660-679.

128 Cfr. Procesos..., t. VI, pp. 679-699.

129 Cfr. Procesos..., t. VI, pp. 700-701.
} 
dre, inscribir a la sierva de Dios entre las santas. Y recordaba con cuánta piedad y vehemencia habían pedido esta canonización los reyes de España Felipe III y Felipe IV, así como el emperador, los reyes de Francia y Polonia, y otros muchos príncipes ${ }^{130}$.

Una semana más tarde, el 1 de febrero, Gregorio XVI presidió el consistorio público en el palacio apostólico, en que el cardenal Giovanni Garzia Millini hizo la «Oratio» para pedir la canonización de la beata virgen Teresa: Se daba un repaso a su vida, ponderando sus virtudes y sus milagros; concluía pidiendo al Sumo Pontífice inscribiese «a esta virgen tan clara, por su insigne santidad» en el catálogo de los santos para público gozo y ejemplo para la Iglesia universal. Al final se recordaba a los papas de este largo recorrido de procesos, esto es, a Clemente VIII, Paulo V; y también se recordaban personajes que se interesaron e impulsaron la canonización: Felipe III y Felipe IV, el emperador Fernando, Luis XIV de Francia, Segismundo rey de Polonia, y otros muchos príncipes, toda la Orden de los Carmelitas Descalzos y toda España ${ }^{131}$.

El secretario del Papa, Juan Ciampolo, daba la respuesta manifestando los sentimientos del Pontífice y diciendo que rogaba a todos que implorasen al Padre de las Lumbres, y que él mismo oiría el consejo de los cardenales de la Iglesia, a los patriarcas, arzobispos y obispos, que habían de determinar ${ }^{132} \ldots$

El 28 de febrero de 1622 Gregorio XV presidió un consistorio semipúblico en que intervinieron cardenales, arzobispos, obispos, etc.; se decretó celebrar la canonización de los cinco Beatos el 12 de marzo de $1622^{133} .26$ cardenales (Francisco María Borbonio de Monte, Francisco María Sfortia, Alessandro Peritti di Montalto, Octavio Bandini, Andreas Peretti de Monte, Dominico Ginnasi, Carlos Madrutius, Scipio Caffarelli-Borghese, Maffeo Barbarini, Giovanni Garzia Millini, Marcelo Lante della Rovere, Juan Bautista Leni, Fabricio Veralli, Dominico Rivarola, Felipe Filonardi, Roberto Ubaldini, Gabriel Trejo Paniagua, Gaspar Borja y Velasco, Guido Bentivoglio, Pedro Valier, Federico de Zollern, Esteban Ajelandro Pignatelli, Luis Ludovisi, Francisco Sacrati, Marcos Antonio Gozzadini, Hipolito Aldobrandini), 1 patriarca (Diofebo Farnese), 8 arzobispos (Galeacio Sanvitale, Filiberto Milliet, Dominico Marini, Paulo Emilio Filonardi, Andrea Gervasio, Alaleonis (?), Marcos Antonio Quirino, Alfonso Gonzaga), 19 obispos (Rafael Inviziati, Julio Sansedoni, Alejandro

\footnotetext{
130 Cfr. Procesos..., t. VI, pp. 703-710.

131 Cfr. Procesos..., t. VI, pp. 711-716.

132 Cfr. Procesos..., t. VI, pp. 711-716.

133 Cfr. Procesos..., t. VI, pp. 717-718.
} 
Caccia, Marino Georgi, Berlingerio Gessi, Jacob Goria, Cosmus Bardi, Sebastián Bouthillier, Lucas Alamani, Octavio Mancini, Pedro Francisco Maletti, Francisco Motini, Luis Sarego, Antonio Díaz, Juan Vicente Spinola, Héctor Diotallevi, Carlos Bovi, Jeronimo dal Pozzo, Antonio Albergati), dieron su voto, expresando cada uno, aunque muy brevemente, la razón de su voto a favor de la canonización de la beata Teresa de Jesús, fundadora de los Carmelitas Descalzos ${ }^{134}$.

\section{BULA DE LA CANONIZACIÓN (12-III-1622)}

El 12 de marzo de 1622 tuvo lugar la canonización, fecha en que Gregorio $\mathrm{XV}$ firmaba y hacía pública la bula «Omnipotens sermo Dei», a continuación de la firma del Papa aparecen las de 36 cardenales.

La bula repasa algunos aspectos de la vida, virtudes y milagros de la madre Teresa de Jesús. Muestra admiración por las grandes cosas que Dios realizaba en aquellos tiempos, pues concretamente «por mano de una doncella suscitó y levantó en su Iglesia, como otra nueva Débora, a una virgen Teresa»...

Recordando algunos aspectos de la vida de la Iglesia, se afirma: «Con tanta firmeza y verdad creía y confesaba los Santos Sacramentos de la Iglesia y los demás dogmas de la Católica Religión, que no podía, como muchas veces ella aseguraba, tener mayor certeza de otra ninguna cosa. Ilustrada y esclarecida esta Santa, con esta antorcha y perspicacia de la fe, muchas veces veía clara y distintamente con los ojos del entendimiento el cuerpo de Jesucristo en la sacratísima Eucaristía, y afirmaba que no tenía cosa alguna que envidiar a los que habían visto al Señor con los ojos corporales».

Resalta las excelencias de sus virtudes, en primer lugar el amor de Dios: «Entre las virtudes de Teresa, fue la principal el amor de Dios, el cual en tanto grado resplandeció en su corazón, que los confesores suyos admiraban y celebraban su caridad como propia, no de mujer, sino de un querubín inflamado»... «Otras veces vio un ángel, que arrojando un dardo como de fuego, la pasaba y llegaba al corazón; con cuyos celestiales dones y beneficios tanto se inflamaba y ardía en el amor de Dios, que enseñaba de Su Majestad, hizo un voto grandemente arduo y dificultoso, de hacer siempre lo que entendiese era más perfecto y más conducía a la mayor gloria de Dios».

134 Cfr. Procesos..., t. VI, pp. 711-716. 
En segundo lugar el amor al prójimo: «pero con cuanta y perpetua caridad hubiese amado y querido al prójimo, existen claros y manifiestos argumentos y señales, principalmente el gran deseo y anhelo con que pretendía la salud de las almas. Lloraba con perpetuas y continuas lágrimas las tinieblas y el poco conocimiento de nuestra fe de los infieles y herejes, y por su reconocimiento y conversión, no tan solamente hacía muchas oraciones, sino también ofrecía ayunos y disciplinas, y con otros exquisitos tormentos afligía y maceraba su cuerpo».

Y además de los dones o gracias que recibió de Dios, se acentúa el aspecto de escritora, «la enriqueció largamente con otros dones y gracias, y la llenó y fecundó de espíritu de inteligencia divina, para que no tan solamente en la Iglesia de Dios diera y dejara ejemplos y dechados de buenas obras, sino esparciera y la ilustrara con los rocíos de la celestial sabiduría, escribiendo tantos libros de mística Teología y otros llenos de mucha piedad, de los cuales los entendimientos y espíritu de los fieles perciben y sacan abundantísimos frutos para el alma, y con ellas son encendidos, elevados y guiados a la patria celestial».

Y hacia el final se dice solemnemente: «Para honra y gloria de Dios y de la individua Trinidad, exaltación y aumento de la fe católica, por la autoridad y omnipotencia del misericordioso Dios, Padre, Hijo y Espíritu Santo, y de los bienaventurados Apóstoles, y por la nuestra, de unánime consejo parecer de los venerables hermanos nuestros de la Santa Iglesia de Roma, Cardenales, Patriarcas, Arzobispos y Obispos, asistentes y residentes en esta romana Curia: determinamos, juzgamos y definimos, que la bienaventurada Teresa virgen, de gloriosa memoria, nacida en la ciudad de Ávila, de cuya santidad, candidez de ánimo y demás excelencias, milagros y virtudes, de las cuales bastantemente nos consta, es santa, gloriosa y alabada. Por lo cual sentimos y estatuimos, definimos y determinamos, que se debe poner, asentar y numerar en el catálogo y número de las santas vírgenes, según y de la forma que por el tenor de las presentes la ponemos, escribimos y alistamos; por lo cual todos los fieles de Cristo la deben reverenciar, venerar y tener por verdadera Santa, y por tal mandamos, queremos y ordenamos sea tenida y reverenciada $\gg^{135}$.

135 Cfr. Procesos..., t. VI, pp. 751-762. Aquí se ha usado la traducción castellana que se publica en Reforma (JOSÉ DE SANTA TERESA, OCD, Reforma de los Descalzos de Nuestra Señora del Carmen de la primitiva observancia becha por santa Teresa de Jesús en la antiquíssima Religión, fundada por el gran Profeta Elías, t. IV, Madrid, 1684) 4, 313-322, traducción que fue publicada también por Silverio de Santa Teresa (BMC 2, 419-430). 


\section{CELEBRACIÓN DE LA CANONIZACIÓN (12-III-1622)}

\section{En Roma}

El secretario de la sagrada congregación hacia el final de las actas escribió con cierto entusiasmo: «Se hizo la canonización célebre y digna de ser recordada por todos los siglos» ${ }^{136}$.

Efectivamente, es conocida la celebración que tuvo lugar el 12 de marzo en la nueva gran basílica de San Pedro en Roma, el rito solemnísimo, que fue la admiración de todos ${ }^{137}$. El secretario de la Congregación describe el espléndido espectáculo del interior de la basílica de San Pedro en el momento de la canonización: su magnitud, hermosura y arquitectura, etc., superiores a las de todas las basílicas del mundo; un anfiteatro increíble ${ }^{138}$.

Hacia el mediodía del 12 de marzo, estando toda la iglesia preparada bajó de su palacio vaticano Gregorio XV, y fue llevado en su silla, antecediéndole los cardenales; bajó junto al altar y se hincó de rodillas; oró a Dios pidiendo acierto en aquel momento para gloria de Dios y honra de los cinco bienaventurados, pues quería canonizarlos. Ya sentados, se presentaron el cardenal Ludovisio, sobrino del Papa, procurador de los cinco beatos, y su abogado el señor Zambecario. Estos hicieron la primera súplica a Pontífice: en nombre del emperador, reyes y príncipes católicos, suplicaban inscribir a Isidro Labrador, Ignacio de Loyola, Francisco Javier, Teresa de Jesús y Felipe Neri en el catálogo de los santos, y que fueran venerados por los fieles.

A esta petición el secretario del Pontífice respondió; y respecto a la beata Teresa decía: «Teresa, coronada de virginales azucenas, y quebrantando en su propio cuerpo las armas de los apetitos, con mortificaciones voluntarias triunfó perpetuamente en la Iglesia militante de las valentías de los demonios. Tuvo familiares coloquios con la Sabiduría eterna, y descubrió los secretos divinos. Hubiera logrado la palma de mártir, si el soberano Esposo, enamorado del sacrificio de su virginal pecho, no la hubiera reservado, para que sin derramar su roja sangre, restituyese sus antiguos verdores al Carmelo».

\footnotetext{
136 Cfr. Procesos..., t. VI, pp. 740.

137 Cfr. Procesos..., t. VI, pp. 740-750; ANTONIO DE SAN JOAQUín, Año teresiano, diario histórico, panegyrico moral, en que se descriven las virtudes, sucesos, y maravillas de la seraphica, y mystica Doctora de la Iglesia Sta. Teresa de Jesús..., t. III, Madrid, 1738, pp. 219-227; Vicente de LA FUENTE, Escritos de Santa Teresa, II, Madrid, 1952, 430-432; BMC 2, 431-436.

138 Cfr. Procesos..., t. VI, pp. 741-743.
} 
A continuación, el papa se arrodilló y oró un rato, mientras el coro cantaba las letanías de los Santos. De nuevo el Pontífice en el trono, el cardenal Ludovisio y su abogado hicieron la segunda súplica, en la misma línea de la primera. A lo que el secretario de Papa respondió: en este asunto tan importante, juzga el Papa que se deben repetir las oraciones de todos para implorar la luz del espíritu divino.

Entonces el Pontífice bajó de su silla, se dirigió a donde estaba el cardenal Este, que hacía de diácono, y vuelto al pueblo dijo: «orad». El Papa se arrodilló, y después de orar en silencio con los cardenales, dijo el diácono: «Levantaos». Se entonó el himno «Veni, Creator Spiritu»; y después de la oración «Deus, qui corda fidelium»..., el Papa se sentó.

Entonces tuvo lugar la tercera súplica, a la que el secretario del Pontífice dijo que éste determinaba conceder los honores celestiales a los cinco beatos. Y el mismo cardenal Ludovisio, acompañado del abogado, dijo: «Beatísimo Padre..., tenga por bien de despachar, en orden a la efectuada canonización, sus apostólicas letras»... Entonces su Santidad respondió: «Así lo decretamos».

Y uno de los Prelados en voz alta leyó la sentencia y decreto de Su Santidad:

«A la honra de la Santa e Individua Trinidad y exaltación de la fe católica y aumento de la Religión cristiana, con la autoridad del mismo Dios Todopoderoso, Padre, Hijo y Espíritu Santo, y de los santos apóstoles Pedro y Paulo y nuestra; habiendo tomado consejo de nuestros hermanos, determinamos y definimos, que los sujetos, de buena memoria, Isidro Labrador, patrón de Madrid; Ignacio de Loyola, del pueblo de Azpeitia, fundador de la Compañía; Francisco Javier, de la misma Compañía de Jesús; Teresa de Jesús y Ahumada, natural de Ávila, fundadora de la Orden de Carmelitas Descalzos; y Felipe Neri, Florentín, fundador de la Congregación del Oratorio, son Santos, dignos de ser escritos en el Catálogo de los Santos y como tales los escribimos en dicho Catálogo»... en el día del tránsito «de Teresa, como a solamente virgen, celebre la universal Iglesia sus oficios devota y solemnemente».

Oído este decreto, «regocijándose todo el concurso y sonando los instrumentos músicos todo era dar voces de alegría y hacer reverencia a los nuevos Santos. Sin detención alguna, hicieron fuera de la iglesia señal de chirimías, las campanas y muchísimas trompetas. Entonces también los soldados suizos, de que se formaba la Guardia de Su Santidad, hicieron salva con repetidos disparos; principalmente en el castillo de San Ángelo se dispararon muchas piezas de artillería, en señal de la canonización de los cinco Santos. También se oía por toda la ciudad el sonido alegre de las campanas. $\mathrm{Y}$ de todo resultaba excitarse mucho los corazones de cuantos fieles había a alabar y bendecir a Dios en sus Santos». 
A continuación el Papa entonó el «Te Deum laudamus»... Después se celebró la misa de San Gregorio, doctor de la Iglesia, con la segunda oración propia de los cinco nuevos santos. En el ofertorio se escenificó una lucida ofrenda de dones: diez cirios grandes, muy hermosamente adornados, así con los escudos de los Santos, como con los del Papa y rey católico...; cinco canastillos dorados y en cada uno dos blancas tórtolas; diez grandes panes; otros cinco canastillos plateados con un par de palomas blancas cada uno; cinco cestillas adornadas de plata y oro, que debajo de redecillas de seda aprisionaban pajarillos, que el papa los liberó, y fueron volando a lo alto del templo. Por santa Teresa hicieron las ofrendas los cardenales Zollern, Gerardo y Scaglia ${ }^{139}$.

Al día siguiente, el 13, hubo una solemne procesión desde San Pedro a Santa María de la Scala, de los carmelitas descalzos ${ }^{140}$.

\section{En el mundo (particularmente en Flandes)}

La canonización de santa Teresa se celebró en muchas naciones; especialmente allá donde la Orden de Carmelitas Descalzos estaba presente, en España sobre todo ${ }^{141}$, pero también en Francia, Italia, Bélgica, Alemania, Polonia, India, etc.; estas celebraciones gozosas se multiplicaron durante el año de 1622.

Inicié este artículo con la muerte de la madre Teresa de Jesús en los brazos de Ana de San Bartolomé; ésta vio la gloria que le esperaba a su maestra, dio su sí a la voluntad de Dios. Ahora la amiga inseparable experimentaba en la tierra el reconocimiento de su santa Madre. Ella había vivido la presencia viva y activa de Dios en Teresa, y la había dado a conocer en Francia y en Flandes... Ahora veía cómo la Santa era alabada y reconocida en el mundo, y particularmente en Flandes, cuya soberanía algunos meses antes había vuelto a la corona de España.

${ }^{139}$ La celebración de la canonización véase t. VI, pp. 740-750. Su traducción castellana, que aquí transcribo, se publicó en ANTONIO DE SAN JOAQUÍN, Año teresiano, diario bistórico, panegyrico moral..., t. III, Madrid 1738, 227-231,Vicente de LA FuENTE, Escritos de Santa Teresa, II, Madrid, 1952, 432-433; BMC 2, 435-436.

140 Cfr. Procesos..., t. VI, pp. 750.

${ }^{141}$ No es ahora el momento para ir enumerando las ciudades y los pueblos de España, en los que las celebraciones religiosas y festejos populares y culturales se multiplicaron, y de los que hay noticias y descripciones, y no sólo respecto a la canonización sino también a la beatificación. Algo de las celebraciones culturales, por ejemplo en Madrid, especialmente respecto a la participación en las literarias de parte de escritores famosos de la época como Lope de Vega, Pedro Calderón de la Barca, Luis de Góngora, Miguel de Cervantes, etc., puede verse en Fidel SEBASTIÁN, Teresa de Fesús, objeto de la literatura, en Monte Carmelo, 123 (2015), pp. 351-401. 
Ana recibía y enviaba parabienes por tan gran acontecimiento de la canonización. Así, por ejemplo, felicitaba y agradecía a la Infanta Isabel Clara Eugenia por su participación en el logro de la gran dicha. Su Alteza debía estar segura de que la Santa se lo pagaría en esta vida y en la otra. Y le suplicaba que mandara se celebrase en Amberes una fiesta en honor de la nueva Santa ${ }^{142}$.

También recibió noticias y felicitaciones del P. General, Matías de San Francisco, cuya carta la recibió «como si viniera del cielo». Ella por su parte le contaba sus experiencias: el día de la canonización lo vivió con gran consuelo, «yo quedé en paz y gozo, que le he tenido de ver esta Santa honrada como lo merece de Dios y de su Santa Iglesia. Bendigamos día y noche al Señor, que la escogió para poner en ella tantas gracias, que es de su gloria mostrarlas en sus amigos, $\mathrm{y}$ en nuestra Santa halló caudal para darlas más que en otros muchos» ${ }^{143}$.

Se congratuló con la priora de las carmelitas inglesas de Amberes. Ver a la madre Teresa canonizada era uno de los contentos que podría tener en este mundo; $\mathrm{y}$ «en quererla y en consolarme de las honras que Dios y el mundo la hacen, no daré a nadie la ventaja en esto» ${ }^{144}$.

En Bélgica todos los conventos carmelitanos festejaron la canonización de manera espléndida. Así conocemos la buena narración de la gran solemnidad con que se celebró en el carmelo femenino de Tournai ${ }^{145}$, o en el de Mons ${ }^{146}$. Así se celebraría también en Bruselas, Lovaina, Malinas, etc.; Ana de San Bartolomé por su parte haría todo lo posible en organizar una gran fiesta religiosa en Amberes.

$\mathrm{Al}$ conocer que el Papa iba a llevar a cabo la canonización, ya a comienzos de febrero pedía a la duquesa Caterina Gonzaga seda para terminar «un ornamento bordado de flores de matices sobre tela de plata con las sedas» que la duquesa le había enviado, y les faltaba más seda para usar el ornamento el día de la canonización $^{147}$.

Para la celebración de la fiesta de la canonización había otra preparación más importante, la espiritual. En esta ocasión el prior de los carmelitas descalzos

142 ANA DE SAN BARTOlOMÉ, Carta 476 (a la Infanta Isabel Clara Eugenia, [Amberes marzo-abril 1622]).

143 ANA De SAn Bartolomé, Carta 478 (al P. Matías de San Francisco, Amberes abril [1622]).

144 Cfr. ANA DE SAN BarTolomé, Carta 485 (a la M. Ana de la Ascensión, [Amberes mayo-junio 1622]).

145 Cfr. Archivo de las Carmelitas Descalzas de KaIn-Les-Tournai, Histoire ou Relation... de Tournay, pp. 42-50.

146 Cfr. Archivo de las Carmelitas Descalzas de Mons, Histoire chonologique du couvent... de Mons, p. 19.

147 ANA DE SAN BARTOLOMÉ, Carta 466 (a la duquesa Caterina Gonzaga, Amberes 11 de febrero 1622). 
de Amberes, P. Hilario de San Agustín, pidió a la madre Ana para los Padres consejos de cómo debían prepararse para este acontecimiento, y la carismática heredera de Santa Teresa les dedicó una carta muy espiritual ${ }^{148}$ : En primer lugar, para aparejarse para la fiesta «a gusto de Dios y de nuestra Santa» era preciso «vestirnos de la vestidura que sacó Cristo nuestro Redentor el día de nuestra redención, que fue de púrpura: vestidura de escarnio y desprecio, y dolores que tuvo en la cruz». Ésta era la vestidura a ponerse en los corazones, pues imitando los misterios de Cristo se podrá hallar vida y espíritu, y todas las acciones serán en espíritu. Esta vestidura «se conservará con la paciencia y humildad y amor, que, sin éste, mal se conocerá el don de estas virtudes, que son las que nuestra Santa traía presentes en sus obras y las que practicó siempre». Siguiendo a «tan valerosa amiga de Dios» invitaba a los Padres a mostrar el amor con obras, ese amor que necesariamente debe estar acompañado de la paciencia y de la humildad.

La fiesta por la canonización en Amberes tuvo lugar el 13 de junio de 1622, según el programa de Ana de San Bartolomé149.

Las crónicas del Carmelo de Amberes, fechadas en $1658^{150}$, acentúan la activa y predominante participación de Anne de Meleun, duquesa de Bournonville, en la solemnización de la fiesta. Además de este relato de las crónicas, conocemos el del libro publicado sobre la vida de los duques de Bournonville ${ }^{151}$.

La duquesa se instaló para este propósito en el convento de Amberes. Organizó y preparó el evento de la fiesta, y ella animó a muchos a participar. No ahorró dineros, ni tiempo ni esfuerzos... Procuró engalanar las calles, especialmente la plaza frente al convento y la iglesia. Delante del convento expuso grandes pinturas representando los principales hechos de la vida de la nueva Santa. Grandes tablones con tapices artísticos, banderas, flores, etc. En la iglesia hizo colgar espléndidos tapices prestados por la Infanta Isabel.

Y la imagen de la Santa, que iba a ser llevada en procesión por la ciudad, estaba colocada bajo un arco de triunfo, vestida de diamantes, perlas, joyas verdaderas y falsas o de adorno, sosteniendo la corona imperial. La estatua (que la Priora había mandado hacer para su beatificación en 1614) estaba adornada al

148 Cfr. Ana de San Bartolomé, Carta 486 (al P. Hilario de San Agustín, [Amberes ca. junio $1622])$.

149 Cfr. ANA DE SAN BARTOlomé, Carta 480 (a la duquesa Caterina Gonzaga, Amberes 27 de mayo 1622).

150 Cfr. ArChivo de las Carmelitas Descalzas de Amberes, ms. H2 a : Histoire ou Relation... d'Anvers.

151 Cfr. Comtesse Marie de Villermont, Le Duc et la Duchesse Bournonville et la Cour de Bruxelles, Bruxelles-Paris, 1904, pp. 140-142. 
estilo español con vestido y manto cubiertos de las joyas de la duquesa, de manera que la misma Infanta quedó sorprendida.

El día de la fiesta por la mañana sonaron las campanas de Amberes, en especial la gran campana de la ciudad, y la población acudió como en grandes fiestas. La clerecía, con sus ornamentos, fue a recoger la estatua de la Santa. La procesión comenzó. Las corporaciones de la ciudad escoltaban y la Infanta Isabel Clara Eugenia con su corte seguía devotamente detrás de la estatua. Las Órdenes religiosas de Amberes, la nobleza, el ejército y el pueblo marchaban en un inmenso cortejo en el que el duque de Bournonville precedía a la estatua de la Santa llevando la bandera del Carmelo. En la puerta de la clausura esperaban las religiosas con la priora Ana de San Bartolomé al frente, momento en el que hubo cantos y oraciones para celebrar a la nueva Santa. Cada minuto hasta la tarde en la fortaleza o castillo de Amberes sonaba un cañonazo o un fuego artificial (para lo cual el eclesiástico Wilts ${ }^{152}$ había donado 1500 libras).

\section{REFERENCIAS BIBLIOGRÁFICAS}

a) Archivos

ArChivo de las Carmelitas Descalzas DE Amberes.

Archivo Provincial de los Carmelitas Descalzos de Gante.

ARChivo de las Carmelitas Descalzas de KaIN-LES-Tournai.

ARChivo de las Carmelitas Descalzas de Mons.

ArChives GÉnÉRAles du Royaume (Bruselas), Negotiations de Rome. Papiers d'État et de l'Audience.

ARCHIVO GENERAL OCD, ROMA.

\section{b) Bibliografia}

ANÓNIMO, Un diario curioso de la canonización de Sta. Teresa, en Monte Carmelo, 27 (1923).

ANTOLÍn, Fortunato, Intervención de Diego de Yepes en favor de la doctrina teresiana, en Revista de Espiritualidad, 190 (1989), pp. 313-318.

152 Pocos meses después se haría carmelita descalzo con el nombre de Elías de Santa Teresa, que trabajaría tan intensamente en los procesos de beatificación y canonización de Ana de San Bartolomé. Era natural de Amberes; profesó en el Carmelo de Lovaina el 21-XI-1623, con 27 años. Murió en Amberes el 6-IX-1640: cfr. ArChIVo Provincial DE los Carmelitas Descalzos DE GANTE, A/II/1/1 ${ }^{\circ}$ : Liber profesionum et necrologium, p. 17. 
ANTONIO DE SAN JOAQUÍN, Año teresiano, diario histórico, panegyrico moral, en que se descriven las virtudes, sucesos, y maravillas de la seraphica, y mystica Doctora de la Iglesia Sta. Teresa de Fesús..., t. III, Madrid, 1738.

Astigarraga, Juan Luis; PACHO, Eulogio y RodrígueZ, Otilio, Fuentes históricas sobre la muerte y el cuerpo de santa Teresa de fesús (1582-1596), Roma, 1982.

BEATA ANA DE SAN BARTOlOmÉ, Obras completas, a cargo de Julen URKIZA, OCD, Monte Carmelo, Burgos, 2014.

ENRIQUE DEL S. CORAZÓn, Santa Teresa de Jesús ante la Inquisición española, en Ephemerides Carmeliticae, 13 (1962), pp. 518-565.

José DE SANTA TeRESA, OCD, Reforma de los Descalzos de Nuestra Señora del Carmen de la primitiva observancia becha por santa Teresa de fesús en la antiquíssima Religión, fundada por el gran Profeta Elías, t. IV, Madrid, 1684.

LA FuenTe, Vicente de, Escritos de Santa Teresa, II, Madrid, 1952.

Llamas, Enrique, Santa Teresa de Jesús y la Inquisición española, Madrid, 1972.

SEBASTIÁN, Fidel, Teresa de fesús, objeto de la literatura, en Monte Carmelo, 123 (2015), pp. 351 401.

URKIZA, Julen, 'Con el mal de la muerte' y 'la hora del dichoso tránsito'. Manifestaciones de un testigo de excepción, en Revista de Espiritualidad, 159-160 (1981), pp. 311-330.

URKIZA OCD (ed.), Julen, Procesos de beatificación y canonización de la madre Teresa de Jesús, 6 tomos, Burgos, 2015-2016.

Villermont, Comtesse Marie de, Le Duc et la Duchesse Bournonville et la Cour de Bruxelles, Bruxelles-Paris, 1904. 